\title{
Foot Drop as a Complication of Weight Loss After Bariatric Surgery - Is It Preventable?
}

\author{
Frank J. M. Weyns ${ }^{1}$, Frauke Beckers'2, \\ Linda Vanormelingen ${ }^{3}$, Marjan Vandersteen ${ }^{3}$ and Erik Niville ${ }^{4}$ \\ ${ }^{1}$ Department of Neurosurgery, Ziekenhuis Oost-Limburg, Genk (B), \\ ${ }^{2}$ School of Life Sciences, Universiteit Hasselt, \\ ${ }^{3}$ Department of Basic Medical Science, Universiteit Hasselt, \\ ${ }^{4}$ Department of Abdominal Surgery, Ziekenhuis Oost-Limburg, Genk (B), \\ Belgium
}

\section{Introduction}

Peroneal neuropathy, causing foot drop, is a common mononeuropathy accounting for approximately $15 \%$ of all the mononeuropathies in adults. (A. Cruz-Martinez, et al. 2000, E. Shahar, et al., 2007) A relationship between peroneal nerve palsy and weight loss has been well documented over the last decades. (D.G. Sherman, et al., 1977, K.A. Sotaniemi ,1984, E. Streib, 1993, I. Aprile et al., 2000, M.J.H. Harrison, 1984) During World War II, foot drop was frequently observed in prisoners of war. Prolonged sitting as well as weight loss were speculated to be the cause of foot drop. (F. Kaminsky. 1947, D. Denny-Brown, 1947) In the sixties, foot drop was also related to cancer. Paraneoplastic phenomena were thought to be the cause of this neurological condition, however all patients with foot drop had significant weight loss due to the primary disease. (D.I. Rubin, et al.,1998) In severe diabetes (with weight loss) also many patients developed peripheral nerve problems. Here, 'diabetic neuropathy' was thought to be the main reason for this condition. During the last decade many reports of foot drop due to starvation or weight loss were published. (A. CruzMartinez, et al. 2000, E. Shahar , et al., 2007, D.G. Sherman, et al., 1977, K.A. Sotaniemi ,1984, E. Streib, 1993, I. Aprile et al., 2000, D.I. Rubin, et al., 1998, P.J. Koehler, et al., 1997, I. Lutte, et al., 1997) It became clear that substantial weight loss itself could cause foot drop. Further study of the pathogenesis of this condition is required.

\section{Material and methods}

In our institution 160 patients were operated for persisting foot drop between January 1995 and December 2005. In all cases an L5 radiculopathy was excluded and a peroneal neuropathy -with a conduction block at the fibular head- was demonstrated by electromyography. When selected, all patients were interviewed to detect the possible cause of their neurological condition. The different pathophysiological conditions are summarized in figure 1 . Weight loss ( $>10 \%$ of body weight) was found in $43.5 \%$ of the patients, the reasons being dieting, bariatric surgery, severe illness (pneumonia, cancer, diabetes,...), psychiatric disorder, etc. 


\section{Cause of peroneal palsy}
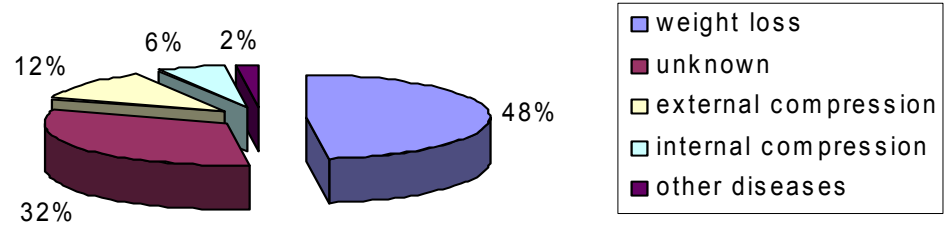

Fig. 1. Cause of peroneal palsy in 160 operated patients: 77 pts with weight loss, 51 pts with unknown cause, 19 pts with external compression (due to positioning ), 10 pts with internal compression ( fibular fracture, haematoma, cystic lesions) and 3 patients with other diseases ( rheumatoid arthritis, diabetes and later diagnosed amyotrophic lateral sclerosis (ALS))

The patients with foot drop following bariatric surgery were compared to a matched control group of patients who did not develop foot drop after bariatric surgery. This control group consisted of patients who all underwent a gastric banding procedure for obesity. Both study groups were statistically similar for sex, age and total weight loss. Statistical analysis was performed using the method of logistic regression and the Chi-square test.

\section{Results}

Between January 1995 and December 2005, 160 patients were operated for persisting foot drop (Figure 2 and 3). Of these 160 patients, 43,5\% (78 patients) developed their pathology after a period of serious weight loss ( $>10 \%$ of their body weight). There were many reasons for this weight loss: dieting, bariatric surgery, severe illness (pneumonia, cancer, diabetes,...), psychiatric disorder, etc. The influence of weight loss on the development of foot drop is clearly demonstrated in this population. This matter will be described in a separate article. In these analyses we noted that the weight loss occurred in a very short period. For all 78 patients maximal weight loss was observed within 18 months (varying from two weeks to 18 months with a mean time interval of 4 months).

Nine patients developed foot drop after bariatric surgery. These patients are listed in table 1 . The mean weight loss for these patients was $45 \mathrm{~kg}$ (38.3\% of their initial body weight), ranging from $20 \mathrm{~kg}$ to $74 \mathrm{~kg}$. This weight reduction took place during a mean period of 8.6 months (ranging from 1 month to 18 months). We compared this patient group with a control group of patients who underwent bariatric surgery (gastric banding) but did not develop peroneal neuropathy. Our control group consists of ten patients, listed in table 2 . The mean weight loss in these patients was $43.8 \mathrm{~kg}$ (38.5\% of their initial body weight), ranging from $23 \mathrm{~kg}$ to $98 \mathrm{~kg}$. The weight reduction took place during a mean period of 21.7 months (ranging from 10 months to 36 months). 


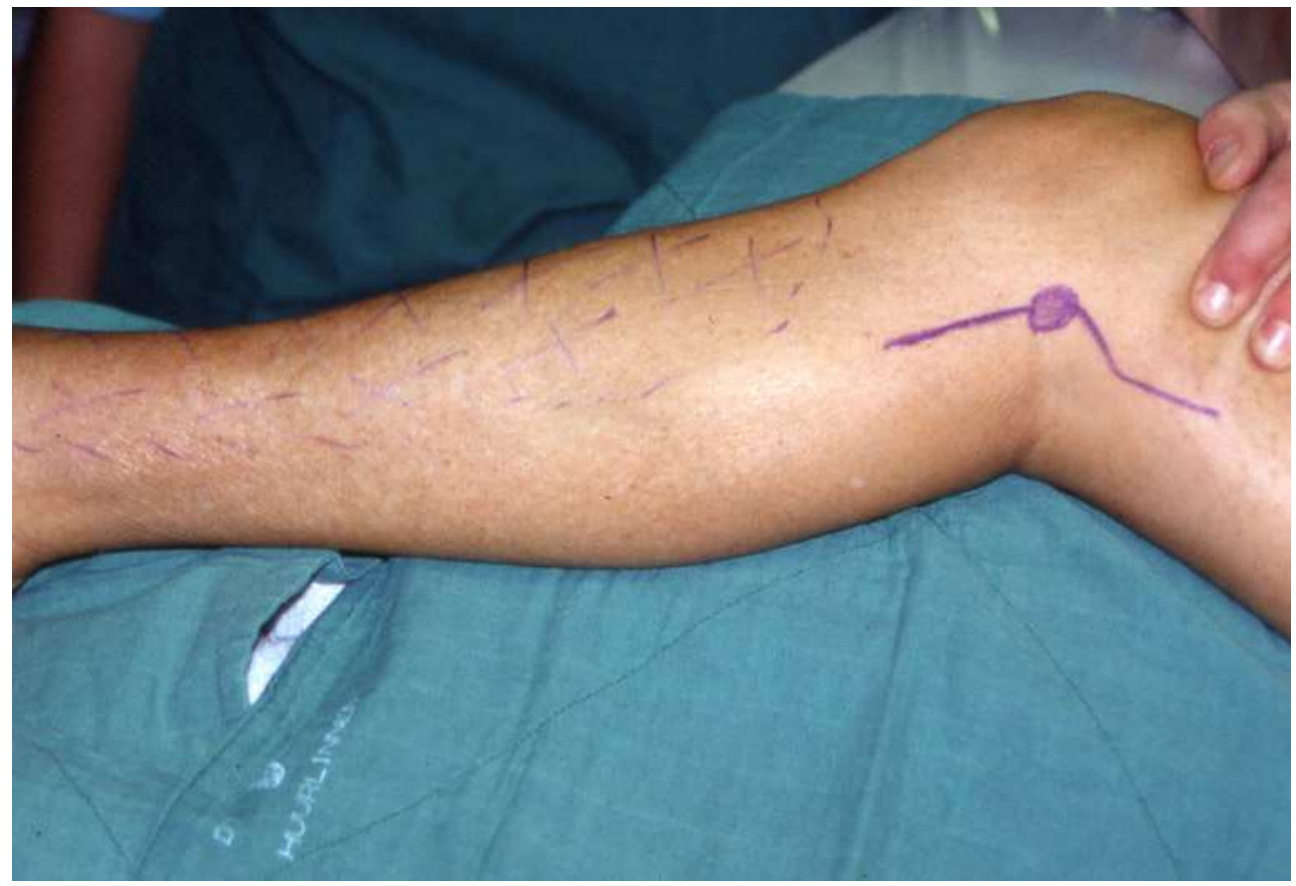

Fig. 2. Incision for peroneal nerve decompression. Dotted line shows the region of sensory deficit. 


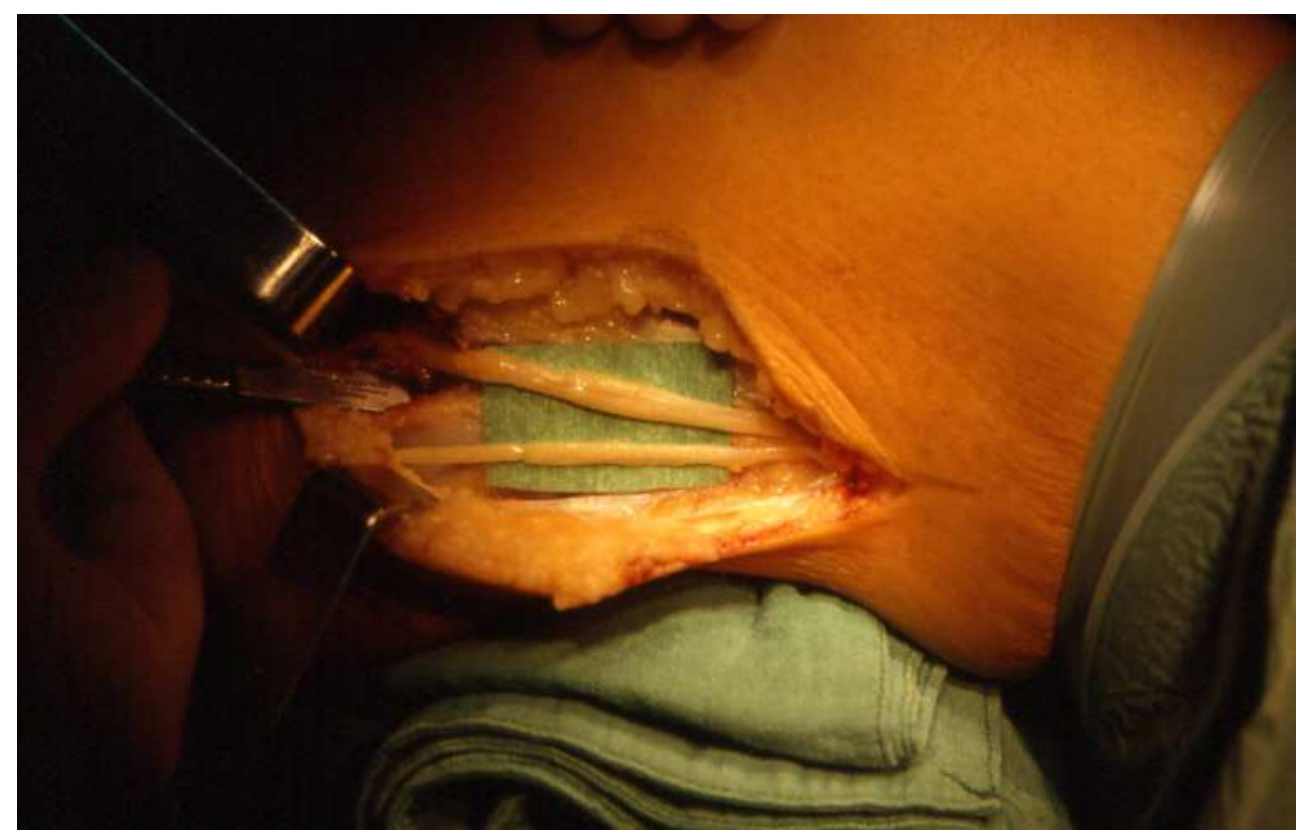

Fig. 3. Peroperative view after decompression of the peroneal nerve with internal neurolysis of the two branches: superficial and deep peroneal nerve. 
Using the Chi-square test, we found statistically significant differences in the amount of weight loss between the two study groups $(\mathrm{p}<0.0457)$. Using the method of logistic regression, we can conclude that weight loss in a short period of time is associated with a higher risk for developing foot drop (Odds ratio $=0.822$ with $95 \%$ reliability interval between 0.678 and 0.996 ). The nerve palsy was resolved by neurolysis of the peroneal nerve at the fibular head in all cases.

\begin{tabular}{|cccccc|}
\hline patient & age & sex & type of surgery & $\begin{array}{c}\text { weight loss } \\
\mathrm{kg}(\%)\end{array}$ & $\begin{array}{c}\text { time period } \\
\text { (months) }\end{array}$ \\
1 & 39 & $\mathrm{M}$ & gastric banding & $50(33 \%)$ & 18 \\
2 & 46 & $\mathrm{~F}$ & bypass & $20(20 \%)$ & 7 \\
3 & 27 & $\mathrm{~F}$ & gastric banding & $28(29 \%)$ & 9 \\
4 & 48 & $\mathrm{~F}$ & gastric banding & $64(46 \%)$ & 12 \\
5 & 45 & $\mathrm{M}$ & bypass & $74(53 \%)$ & 7 \\
6 & 45 & $\mathrm{~F}$ & bypass & $64(50 \%)$ & 6 \\
7 & 22 & $\mathrm{~F}$ & bypass & $42(38 \%)$ & 5 \\
8 & 30 & $\mathrm{~F}$ & gastric banding & $30(37 \%)$ & 6 \\
9 & 40 & $\mathrm{~F}$ & gastric banding & $34(39 \%)$ & 7 \\
\hline
\end{tabular}

Table 1. Nine patients developed foot drop after bariatric surgery

\begin{tabular}{|cccccc|}
\hline patient & age & sex & type of surgery & $\begin{array}{c}\text { weight loss } \\
\mathrm{kg}(\%)\end{array}$ & $\begin{array}{c}\text { time period } \\
\text { (months) }\end{array}$ \\
1 & 37 & $\mathrm{~F}$ & gastric banding & $39(39 \%)$ & 36 \\
2 & 27 & $\mathrm{~F}$ & gastric banding & $29(30 \%)$ & 18 \\
3 & 50 & $\mathrm{~F}$ & gastric banding & $98(58 \%)$ & 36 \\
4 & 44 & $\mathrm{~F}$ & gastric banding & $33(39 \%)$ & 18 \\
5 & 54 & $\mathrm{~F}$ & gastric banding & $29(24 \%)$ & 12 \\
6 & 19 & $\mathrm{~F}$ & gastric banding & $50(38 \%)$ & 24 \\
7 & 57 & $\mathrm{~F}$ & gastric banding & $39(42 \%)$ & 21 \\
8 & 30 & $\mathrm{~F}$ & gastric banding & $41(42 \%)$ & 30 \\
9 & 49 & $\mathrm{M}$ & gastric banding & $47(37 \%)$ & 12 \\
10 & 46 & $\mathrm{M}$ & gastric banding & $39(36 \%)$ & 10 \\
\hline
\end{tabular}

Table 2. Ten control patients without peroneal palsy. 


\section{Discussion}

Peroneal nerve palsy is a common mononeuropathy accounting for approximately $15 \%$ of all the mononeuropathies in adults.( A. Cruz-Martinez, et al. 2000, E. Shahar, et al., 2007) As early as 1876, it was recognized that some patients with chronic disease, developed peroneal nerve palsies.(13,14) While weight loss may have played a role, the neuropathy was generally ascribed to a toxin or infectious agent. In 1929 Woltman was the first author to report the association of massive weight reduction to the existence of foot drop. In 1947 Kaminsky as well as Denny-Brown reported several cases of peroneal nerve palsy in prisoners of war (up to $10 \%$ of prisoners) and attributed this neurological condition to the prolonged dietary restriction. Later peroneal nerve palsy was correlated to cancer.( D.I. Rubin DI, et al., 1998) In a population of more than 400, 000 patients (in which more than 8000 newly diagnosed cases of cancer), Koehler et al. found a relative risk of 8,6 to develop peroneal nerve palsy compared with patients without cancer.( P.J. Koehler, et al., 1997) A paraneoplastic factor or neurotoxicity due to the use of different antineoplastic drugs were considered to cause this syndrome. (P.J. Koehler, et al., 1997) Here as well, malnutrition and secondary weight loss were mentioned as side-phenomena.

Over the last decades, the correlation between weight loss and peroneal neuropathy was well documented. (A. Cruz-Martinez, et al. 2000, D.G. Sherman, et al 1977, K.A. Sotaniemi ,1984, E. Streib, 1993, I. Aprile et al., 2000, M.J.H. Harrison, 1984) In 1977 Sherman et al. described this correlation in 7 patients after excessive weight loss. In their study weight reduction was the only obvious common feature to all their patients. Cruz-Martinez et al. (2000) demonstrated a peroneal neuropathy due to excessive weight loss in $20 \%$ of 150 patients with peroneal symptoms. There were many reasons for this weight loss: dieting, bariatric surgery, psychiatric disorders and other severe diseases like cancer, diabetes, acute pneumonia, etc.( E. Shahar, et al., 2007, M.J.H. Harrison, 1984, D. Denny-Brown, 1947, D.I. Rubin DI, et al., 1998, B.E. Sprofkin, 1958, E.W. Massey, J.M. Massey, 1987, G.D. Scott, 1979) Until now the exact way in which weight loss causes nerve palsy, is still unknown. We consider it due to a compression syndrome caused by nerve oedema as it is known in diabetic neuropathy. This intraneural oedema, caused by metabolic changes can cause nerve dysfunction especially at risk areas (anatomical tunnel regions). Electromyographic studies in all our patients confirmed peroneal nerve palsy with a conduction block at the fibular head. For this reason, we operated upon all patients with persisting foot drop longer than 3 weeks. Up until now, there are controversies upon the optimal therapy for this specific condition. In literature, there are no large studies comparing the conservative and the surgical treatment of peroneal neuropathy in this condition. Recovery after conservative treatment varies strongly from study to study and most of these studies deal with only small groups of patients. (A. Cruz-Martinez, et al. 2000, E. Shahar, et al., 2007, D.G. Sherman, et al. 1977, K.A. Sotaniemi ,1984, E. Streib, 1993, D.I. Rubin DI, et al., 1998, E.W. Massey, J.M. Massey, 1987)

We were also able to demonstrate a statistically significant correlation between weight loss and peroneal neuropathy. In addition we illustrated the short time interval in which the weight loss occurred ( 2 weeks to 18 months with an average of 4 months). These findings are described in a separate article. To investigate the importance of the period in which patients develop their weight loss, especially in a population of bariatric surgery patients, a 
comparison was made between a subgroup of our peroneal nerve palsy patients and a matched control group of patients who were submitted for bariatric surgery (gastric banding) but did not develop peroneal neuropathy. Of the 160 patients who were treated surgically for persisting peroneal nerve palsy, 9 patients developed foot drop after obesity surgery (table 2). The mean weight loss for these patients was $45 \mathrm{~kg}$ ( $38.3 \%$ of their initial body weight). The weight reduction took place during a mean period of 8.6 months. Our control group consisted of 10 patients(table 2). The mean weight loss for these patients was $42.6 \mathrm{~kg}$ ( $37.4 \%$ of their initial body weight). The weight reduction took place during a mean period of 21.7 months.

In contrast to earlier studies (eg. Waldström et al., 1991), we demonstrated that important weight loss is correlated with a higher risk to develop foot drop and that the time period in which the weight loss is achieved is important. A rapid reduction of body weight is correlated with a higher risk to develop foot drop. A slow weight reduction is recommended to avoid such disabling disease.

\section{References}

Aprile I, Padua L, Padua R et al. Peroneal mononeuropathy: predisposing factors and clinical and neurological relationships. Neurol Sci 2000; 21: 367-371

Cruz-Martinez A, Arpa J, Palau F. Peroneal neuropathy after weight loss. J Periph Nerv Syst 2000; 5: 101-105

Denny-Brown D. Neurological conditions resulting from prolonged and severe dietary restriction. Medicine 1947; 26: 41-113

Harrison M J H. Peroneal neuropathy during weight reduction. J Neurol Neurosurg Psych 1984; 47: 1260

Kaminsky F. Peroneal palsy by crossing the legs. JAMA 1947; 134: 206

Koehler PJ, Busher M, Rozeman CAM et al. Peroneal nerve neuropathy in cancer patients: a paraneoplastic syndrome? J Neurol 1997; 244: 328-332.

Lutte I, Rhys C, Hubert C et al. Peroneal nerve palsy in anorexia nervosa. Arch Neurol Belg 1997; 97: 251-254

Massey EW, Massey JM. Peroneal palsy in depressed patients. Weight loss, psychomotor retardation predispose patients to this condition. Psychosomatics 1987; 28: 93-94.

Rubin DI, Kimmel DW, Cascino TL. Outcome of peroneal neuropathies in patients with systemic malignant disease. Cancer 1998; 83: 1602-1606.

Scott G D. Anorexia nervosa presenting as foot drop. J Neurol Neurosurg Psych 1979; 55: 58 60

Shahar E, Landau E, Genizi J. Adolescence peroneal neuropathy associated with rapid marked weight reduction: case report and literature review. Eur J Paediatr Neurol 2007; 11: 50-54

Sherman DG, Easton JD. Dieting and peroneal nerve palsy. JAMA 1977; 238: 230-231.

Sotaniemi KA. Slimmer's paralysis - peroneal neuropathy during weight reduction J Neurol Neurosurg Psych 1984; 47: 564-566.

Sprofkin B E. Peroneal paralysis. A hazard of weight reduction. Arch Intern Med 1958; 102: 82-87

Streib E. Weight loss and foot drop. Iowa Med 1993; 83: 224-225 
Wadström C, Backman L, Persson HE et al. The effect of excessive weight reduction on peripheral and central nervous functions. A study in obese patients treated by gastric banding. Eur J Surg 1991; 157: 39-44.

Woltman H W. Crossing of the legs as a factor in the of peroneal palsy. J Am Med Assoc 1929; 93/ 670-672 


\section{ADVANCED}

BARIATRIC AND

METABOLIC SURGERY

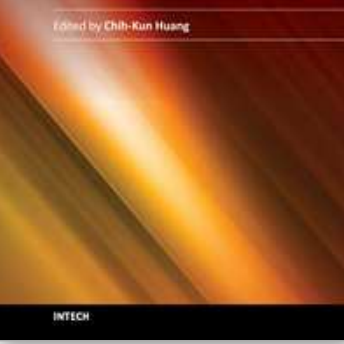

\section{Advanced Bariatric and Metabolic Surgery}

Edited by Dr. Chih-Kun Huang

ISBN 978-953-307-926-4

Hard cover, 326 pages

Publisher InTech

Published online 29, February, 2012

Published in print edition February, 2012

Bariatric surgery has gained importance in the last 20 years because of the high prevalence of global obesity, and the vast understating of the physiological and pathological aspects of obesity and associated metabolic syndromes. This book has been written by a number of highly outstanding authors and pioneering bariatric surgeons from all over the world. The intended audience for this book includes all medical professionals involved in caring for bariatric patients. The chapters cover the choice of operation, preoperative preparation including psychological aspect, postoperative care and management of complication. It also extends to concept and result of metabolic surgery and scarless bariatric surgery.

\section{How to reference}

In order to correctly reference this scholarly work, feel free to copy and paste the following:

Frank J. M. Weyns, Frauke Beckers, Linda Vanormelingen, Marjan Vandersteen and Erik Niville (2012). Foot Drop as a Complication of Weight Loss After Bariatric Surgery - Is It Preventable?, Advanced Bariatric and Metabolic Surgery, Dr. Chih-Kun Huang (Ed.), ISBN: 978-953-307-926-4, InTech, Available from: http://www.intechopen.com/books/advanced-bariatric-and-metabolic-surgery/foot-drop-after-excessive-weightloss

\section{INTECH}

open science | open minds

\section{InTech Europe}

University Campus STeP Ri

Slavka Krautzeka 83/A

51000 Rijeka, Croatia

Phone: +385 (51) 770447

Fax: +385 (51) 686166

www.intechopen.com

\section{InTech China}

Unit 405, Office Block, Hotel Equatorial Shanghai

No.65, Yan An Road (West), Shanghai, 200040, China 中国上海市延安西路65号上海国际贵都大饭店办公楼 405 单元

Phone: +86-21-62489820

Fax: +86-21-62489821 
(C) 2012 The Author(s). Licensee IntechOpen. This is an open access article distributed under the terms of the Creative Commons Attribution 3.0 License, which permits unrestricted use, distribution, and reproduction in any medium, provided the original work is properly cited. 